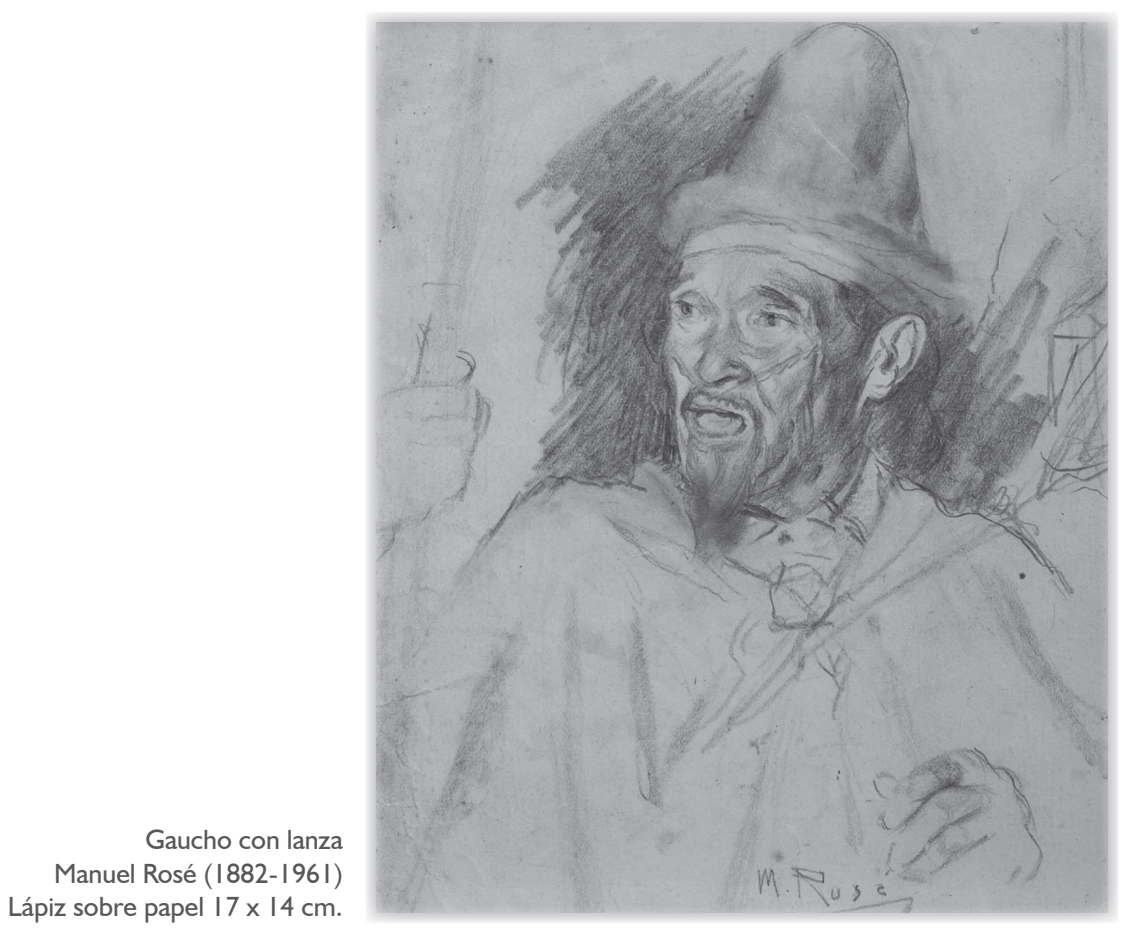

\title{
Sobre historias entrelazadas y otras conexiones
}

El presente número de Humanidades: Revista de la Universidad de Montevideo presenta una selección de estudios basados en las ponencias de las VIII Jornadas de Historia y Cultura de América (2017), organizadas por el Departamento de Historia de la Facultad de Humanidades de la UM y el CEDEI. Desde el comité organizador de éstas jornadas se propuso a las "historias entrelazadas" como tema articulador, entendidas éstas como investigaciones y narrativas históricas tendientes a unir a las Américas entre sí y con otras partes del mundo en una variedad de temáticas. Según lo propuesto en la convocatoria a las jornadas, el tema elegido surgía desde un interés por mirar "más allá de lo local" en un sentido estricto e introspectivo y en un esfuerzo por fomentar la investigación, a nivel local y latinoamericano, en 
marcos de historias comparativas, transnacionales, conectadas y por qué no, globales.

Algunos de los estudios seleccionados para este volumen son el resultado de investigaciones que muestran un esfuerzo por conectar temáticas en la historia latinoamericanista, o incluso de la historia de sitios específicos de las Américas, con eventos o movimientos que trascendieron a estas localidades. El segundo vector intelectual que anima los estudios seleccionados para este volumen es la puesta en valor de América Latina en el contexto de fenómenos de alcance global o supra-regional -como la intensificación del intercambio intelectual y los viajes de exploración arqueológica del siglo XIX-. Interesa en esta presentación, entrelazar cada uno de los trabajos incluidos en este número con algunos debates y discusiones que van más allá de sus objetos de estudio específico y que los vinculan a cuestiones historiográficas y metodológicas sobre las historias conectadas, entrelazadas y globales. Si bien ciertos temas y clivajes desbordan lo que puede ser una definición estricta de las historias entrelazadas, conviene exponer algunos de los géneros o sub-géneros que proponen historias de mayor escala. Junto a la cuestión de la escala está aquella de la conexión. Dicho de otra manera: más relevante que ampliar el foco de estudio a unidades de análisis de carácter más grande, es el rescatar las historias locales o localizadas de un contexto de aislamiento o mera conexión con los relatos vinculados a lo nacional.

Las propuestas en favor de historias de una mayor escala y las que dan cuenta de conexiones y comparaciones, por cierto, no han estado exentas de críticas. Algunas dudas, como veremos, apuntan a los fundamentos ideológicos que sustentan ciertas historias de gran escala. Surgidas en el contexto de la crítica a las historias nacionales, estas nuevas historias de dimensión mayor -desde las historias oceánicas, las historias transnacionales, la historia global, entre otros subgéneros o propuestas que acentúan lo conectado y lo comparativo- bregan, al decir de dos historiadores, por unidades de análisis que estén "por encima o por debajo de lo nacional o lo regional". Sin embargo, estas nuevas propuestas tienen sus propios riesgos en caso de no ser adecuadamente provincializadas - por usar la expresión que popularizó Dipesh Chakrabarty-. Es decir, la tentación de la hegemonía de las historias de mayor escala ha provocado que algunas voces expresen críticas o un cierto escepticismo respecto a 
una posible colonización por parte de las grandes escalas de otros géneros como las historias locales, la microhistoria y las historias ancladas en "lo subjetivo".

Otras voces críticas insisten en que las definiciones espaciales y cronológicas tomadas por quienes realizan investigaciones históricas, dependen de una cantidad de variables de carácter contingente. Entre estas consideraciones se encuentra la libertad individual de los investigadores y sus propias curiosidades intelectuales. El argumento respecto a este punto es que, la defensa a ultranza de ciertos modos de hacer historia por encima de otros pone en riesgo la necesaria pluralidad de nuestra disciplina. La crítica también ha notado las dificultades en términos de recursos materiales que enfrentan los investigadores. Las historias que buscan cubrir escalas mayores son, casi inexorablemente, de carácter más costoso y parecerían confinadas a ser llevadas a cabo desde lugares e instituciones con mayores recursos materiales. El riesgo respecto a este último punto radica en traducir la hegemonía de recursos en una renovada hegemonía intelectual ejercida y proyectada desde ciertos sitios -Norteamérica y Europahacia el resto del mundo. ${ }^{2}$

Con atención a estas críticas, algunas de las cuales serán desarrolladas en las siguientes líneas, esta introducción no es un llamado a la acción o una apología de un género o de una manera de hacer historia en particular. ${ }^{3}$ Antes bien, es una presentación -ni siquiera un estado de la cuestión- de algunas discusiones actuales, realizada a modo de contextualización de la propuesta presentada aquí.

Los estudios contenidos en este número de Humanidades dan

\footnotetext{
$1 \mathrm{Al}$ respecto puede verse el siguiente intercambio entre varios historiadores: Sebouh David Aslanian, Joyce E. Chaplin, Ann McGrath y Kristin Mann, "AHR Conversation: How Size Matters: The Question of Scale in History”, The American Historical Review 118:5 (Dic. 2013): pp. 1431-1472.

2 Sobre este punto puede verse el siguiente pasaje en un ensayo sobre historia global recientemente publicado por los historiadores Richard Drayton y David Motadel: "How many historians outside rich universities in rich countries have access to books, or can travel easily to the foreign archives and conferences that they should need to play the game of 'global history'? As Boubacar Barry, the doyen of history in Senegal, asked the opening plenary of the European Network in Universal and Global History conference in Paris in 2014, what exactly did 'global history' mean when Africans like himself found almost impossible to obtain a Schengen visa?" Richard Drayton y David Motadel, "Discussion: The Futures of Global History", Journal of Global History 13 (2018), p. 8.

3 Tal vez la obra más explícitamente programática en defensa de historias de gran escala desde lo cronológico es: David Armitage y Jo Guldi, The History Manifesto (Nueva York: Cambridge University Press, 2014). Esta obra suscitó una respuesta crítica que cuestiona algunos de los supuestos manejados por Armitage y Guldi: especialmente que las investigaciones históricas desde la profesionalización de la historia académica han tendido a centrarse en escalas temporales menores. Deborah Cohen y Peter Mandler, "The History Manifesto: A Critique", The American Historical Review 120:2 (Abr. 2015): pp. 530-542.
} 
testimonio de las posibilidades metodológicas a la hora de escribir historias entrelazadas. En este sentido, los textos no ofrecen una visión monolítica respecto a escalas espaciales o cronológicas. Antes bien, los trabajos de este número de Humanidades presentan a los lectores varios "juegos de escala". ${ }^{4}$ En términos de escalas temporales, por ejemplo, si bien todos los estudios se insertan dentro del rango de cronologías relativamente breves, al mismo tiempo conectan ese núcleo cronológico de la investigación con otras duraciones.

El artículo de Gabriela Lupiañez sobre la noción de "pueblo" en San Miguel de Tucumán cubre, en profundidad, los años de la invasión inglesa al Río de la Plata. Sin embargo, la preocupación cronológica por la "coyuntura", definida así por la propia autora, no excluye la ubicación del objeto de estudio en relación a otras escalas temporales. Así, el estudio de Lupiañez despliega un doble juego desde el punto de vista cronológico: por una parte, da cuenta del peso de las estructuras -se puede decir de las largas duracionesdel lenguaje hispánico en torno a la noción de "pueblo" y, por la otra, muestra las posibilidades abiertas por la coyuntura para dar una renovada visibilidad a una cierta conceptualización del pueblo. ${ }^{5}$

El trabajo de Estefanía Blasco sobre la producción de imágenes, de las antigüedades mesoamericanas del artista inglés Frederick Cartherwood, también parte desde una escala cronológica relativamente reducida: la expedición organizada por el abogado estadounidense John Stephens en 1839 y la publicación de Views of Ancient Monuments in Central America de Cartherwood, a mediados de la década de 1840. El lustro cubierto por el núcleo del artículo de Blasco también aparece conectado a otras escalas en términos de duración. Blasco reconoce que el trabajo como ilustrador del territorio mesoamericano de Cartherwood, a comienzos de la década de 1840 , no puede entenderse sin insertarlo en una duración de escala mayor

\footnotetext{
4 Tomando la expresión de Jacques Revel, esta es una sugerencia presentada por Richard Drayton y David Motadel en un escrito reciente sobre el futuro de las historias globales: "in our moment ... a self-conscious global history neither neglects 'the small spaces' nor evades the specificity and strangeness of disconnected historical experience. It is instead an invitation to the historian to be self-conscious of the jeux d'echelles, of the interdependence of the scales of space -village, province, nation, region, and world- and time -days, decades, centuries- through which we explore and explain the past.” Drayton y Motadel, “The Futures”, p. 13.

5 Sobre la larga duración en la historia intelectual: David Armitage, "What's the Big Idea? Intellectual History and the longue durée”, Times Literary Supplement, Londres, 21 de setiembre de 2012, pp. 13-15. Gabriel Entín, “'La interconectividad del pasado debería hacernos más humildes ante la globalización del presente’ Entrevista a David Armitage", Nuevo Mundo Mundos Nuevos, puesto online 29 de marzo de 2012. http://journals.openedition.org/ nuevomundo/62721; DOI : 10.4000/nuevomundo.62721
} 
que casi comienza con la era de las exploraciones y de los descubrimientos. Blasco nota las ambigüedades y cambios ocurridos en el curso de la elaboración de relatos e imágenes de exploraciones en territorios americanos, desde el siglo XVI hasta mediados del XIX. Tal vez lo más notable en este caso sean las distintas preocupaciones de los exploradores y el diverso outillage mental de los distintos individuos y grupos. El trabajo de Cartherwood y la expedición de Stephens, participan, entonces, en la larga duración de la exploración y la producción de literatura e imágenes sobre las culturas originarias de América Central. Pero, al mismo tiempo, Blasco sostiene la singularidad de la "visión" propuesta por Cartherwood: la de sostener "el valor absoluto de los americanos como constructores" de las ciudades y monumentos de Yucatán.

Los estudios de Gabriel González Núñez y Carolina Porley proponen miradas menos acotadas desde el punto de vista cronológico, aunque también muestran una cierta interacción entre escalas de tiempo. El texto de Carolina Porley sobre las pinacotecas de Félix Ortiz de Taranco y Fernando García Casalia se centra en los treinta años de madurez (c. 1910-1940) de ambos personajes históricos. El estudio se inserta, preferentemente, en la duración de los "lifespans" o lapsos de vida activa de las personas. Si bien esta escala cronológica ha sido objeto de crítica y debate reciente $^{6}$, es importante notar que Porley, al igual que los demás colaboradores de este número, no se limita a analizar las vidas de Ortiz de Taranco y García Casalia de un modo aislado. Antes bien, desde el punto de vista cronológico este trabajo se entrelaza con otras duraciones. Por ejemplo, uno de estos entrelazamientos es con el hispanismo -o más apropiadamente el de los hispanismos-, como corriente y preocupación intelectual. El coleccionismo de ambos protagonistas se inserta dentro de las fluctuaciones y ansiedades intelectuales en torno a la historia y cultura hispanas. Los puntos de referencia más próximos al trabajo de Porley son, sin lugar a dudas, la revalorización de la cultura hispana ocurrida después de 1898 y la cercanía a los centenarios de 1910 , cuando pensadores españoles como Rafael de Altamira recorrieron

\footnotetext{
6 La crítica a esta escala temporal ha sido articulada con mayor fuerza por Armitage y Guldi, por ejemplo, cuando dicen: "Whether undergraduates, graduate students, or faculty, most people who work with data about time have been trained to examine the past on the scale of an individual life, not the trans-generational perspective on the rise and fall of institutions that characterised the longue durée. As students in classroom were told to narrow and to focus, the professionals who deal with past and future began to restrict not only their sources and their data, but sometimes also their ideas." The History Manifesto, p 40.
} 
Hispanoamérica en una tarea de puesta en valor de la "tradición española”. Lo español como problema, sin embargo, trasciende el '98 y el '10. Las ansiedades sobre la inferioridad española pueden retrotraerse a las primeras articulaciones de la leyenda negra, e incluso a visiones del español como el otro por parte de actores del mundo anglo-protestante. ${ }^{7}$ En ese empeño, además, es notorio un hispanismo de largo cuño y de carácter celebratorio del imperio. ${ }^{8} \mathrm{Al}$ insertar el coleccionismo de Ortiz de Taranco y García de Casalia dentro del marco de los hispanismos, la investigación de Porley entra en diálogo con duraciones que exceden las vidas de estos interesantes actores históricos.

El texto de González Núñez también lidia con un lapso de unos cuarenta años durante la era de las revoluciones, desde finales del siglo XVIII hasta los últimos años de la década de 1820. El estudio de González Núñez, centrado en las traducciones producidas en el marco de las revoluciones de los Estados Unidos, la francesa y las hispánicas, también presenta conexiones con cronologías más amplias. Al insertarse en el marco de los estudios sobre la traducción en Hispanoamérica, el texto de González Núñez presenta conexiones evidentes con las traducciones que antecedieron a las producidas en la era de las revoluciones y también con la intensa producción y el intercambio intelectual más allá de los compases finales de la década de 1820 .

González Núñez, al igual que ocurre con las autoras presentes en este número, destaca por su énfasis en las circulaciones, transferencias e interconexiones entre distintas partes del mundo. Las traducciones de textos en la era de las revoluciones es un tópico conocido. La circulación de textos, particularmente entre ambas orillas del Atlántico norte, fue clave para la formulación de ciertos constructos historiográficos como la historia atlántica de la primera hora -emergida en las décadas de 1950 y 1960 - con trabajos como The Age of Democratic Revolution, de Robert Palmer; o, Les Révolutions, 1770-1799, de Jacques Godechot. Esta primera historia atlántica entroncó con textos como The Rise of the West, de

\footnotetext{
Sobre la construcción del español como el otro: Eric Griffin, "From Ethos to Ethnos: Hispanizing 'the Spaniard' in the Old World and the New", CR: The New Centennial Review 2:1 (Spring 2002): pp. 69-116. Sobre la centralidad de la experiencia hispánica respecto del Nuevo Mundo, frecuentemente vista como algo periférico respecto a la experiencia anglo-protestante puede verse: Jorge Cañizares-Esguerra, Puritan Conquistadors: Iberianizing the Atlantic, 1550-1700 (Stanford: Stanford University Press, 2006).

8 Alda Blanco, Cultura y Conciencia Imperial en la España del siglo XIX (Valencia: Publicaciones de la Universidad de Valencia, 2012).
} 
William McNeil, que dio una gran proyección al estudio de la civilización occidental bañada por el Atlántico norte. Las historias marcadas por el "internacionalismo de la Carta del Atlántico", inicialmente excluyeron a América Latina como área de interés en sí mismo. ${ }^{9}$ Si había una historia de las revoluciones en el hemisferio sur, la misma era -conforme a esta posición- una mera derivación o proyección de los acontecimientos del hemisferio norte. ${ }^{10}$

El texto de González Núñez ofrece al lector un panorama conciso y sintético, pero voluminoso en términos de la cantidad de obras reseñadas, sobre las traducciones que surcaron y unieron distintas partes del Atlántico en los compases finales del XVIII y los comienzos del XIX. El autor propone revalorizar la influencia de los textos ingleses $y$ franceses en el contexto de las revoluciones hispánicas; sin embargo, esta puesta en valor no es un mero resucitar de las tesis de Godechot y Palmer. Antes bien, González Núñez ofrece una visión desde el punto de vista intelectual, acerca de la historia de la prensa y de la imprenta, mucho más matizada. Esto, quizás, es más ostensible en el apartado dedicado a las traducciones que surcaron el Atlántico de sur a norte, con la traducción - por ejemplo-de fragmentos de la Gazeta de Caracas al inglés y su reproducción en varias publicaciones periódicas de la América española en el mundo atlántico anglosajón.

No solo por esa diferente direccionalidad que no es únicamente difusionista norte-sur, el trabajo de González Núñez aparece más vinculado a una "nueva" historia atlántica que al planteamiento emergido en los años ' 50 del siglo pasado. ${ }^{11}$ Antes bien, el texto sin definirse así explícitamente, cumple con una de las premisas de la historia atlántica bien entendida: "ser interactiva y cruzar fronteras". 12 Además de dar testimonio de interconexiones y movilidades, el artículo de González Núñez trae a colación una revalorización de la pluralidad de agentes de las

\footnotetext{
9 La expresión es de Jeremy Adelman. "What is Global History Now?”, AEON, 2 de marzo de 2017, disponible en línea: https://aeon.co/essays/is-global-history-still-possible-or-has-it-had-its-moment

${ }^{10}$ Para una crítica de la exclusión de los mundos atlánticos ibéricos en la narrativa de la era de las revoluciones y las maneras en las que han sido integrados en nuevas narrativas sobre este período: Gabriel Paquette, "The Study of Political Thought in the Ibero-Atlantic World During the Age of Revolutions”, Modern Intellectual History 10:2 (2013): pp. 437-448.

11 Federica Morelli y Alejandro Gómez, "La Nueva Historia Atlántica: Un Asunto de Escalas", Nuevo Mundo Mundos Nuevos, puesto en línea: 6 de abril de 2006, URL : http://journals.openedition.org/nuevomundo/2102 ; DOI: $10.4000 /$ nuevomundo.2102

12 "Second, some Atlantic history must be interactive and cross borders." Philip D. Morgan y Jack P. Greene, "Introduction: The Present State of Atlantic History", Atlantic History a Critical Appraisal, Philip D. Morgan y Jack P. Greene eds. (Nueva York: Oxford University Press, 2009), p. 22.
} 
traducciones en este período. Al poner en valor a actores históricos como Vicente Pazos Kanki, el estudio de González Núñez se muestra en sintonía con una historia "atlántica" que da cuenta de la pluralidad de actores en los mundos atlánticos. ${ }^{13}$ La movilidad física a su rol como desplazadores y relocalizadores en el intercambio intelectual. El estudio de Gónzalez Núñez también cumple con otra característica de la historia atlántica más reciente, en cuanto pluraliza los espacios dónde se desarrollaron conexiones o contactos. Luego de mostrar un rico repertorio de traducciones y traductores, este artículo deja la puerta abierta para nuevas investigaciones en este campo. Una pregunta que queda pendiente de respuesta tiene que ver con las dimensiones materiales de la práctica de las traducciones y con las transferencias entre manuscritos e impresos. Si vemos estas traducciones como 'productos' culturales, ¿acaso queda la puerta abierta para una metodología, al menos parcial, como la que se

aplica a distintos commodities? Los llamados commodity studies, por su parte, aparecen como un subgénero predilecto de la historia atlántica más reciente. Se trata de un campo particularmente rico en la historia atlántica. ${ }^{14}$

Si el artículo de González Núñez se posiciona desde un punto de vista 'macro' o con una visión atlántica de conjunto, otros de los estudios en este número juegan con distintas escalas en cuanto al espacio. El estudio de Lupiañez pone al lector en la encrucijada entre marcos locales, imperiales y atlánticos más extensos. El prisma de la competencia entre imperios es quizás el más amplio en este estudio y el que actúa como contexto general -en tanto la temática descripta se desarrolla en el contexto de la invasión inglesa al Plata. El escenario más local de este estudio, San Miguel de Tucumán, en el interior profundo del virreinato del Río de la Plata, pone de relevancia la integración de un hinterland en la historia atlántica. Algunos historiadores han planteado si la historia atlántica es meramente una historia de las

\footnotetext{
13 Morelli y Gómez notan cómo la inclusión de otros atlánticos como el "Black. Atlantic o Atlántico Negro" han sido clave en poner la historia atlántica más allá de la narrativa de los "orígenes comunes" de la civilización occidental. De esa pluralización también dan cuenta Morgan y Greene en su Atlantic History: A Critical Appraisal.

${ }_{14}$ Un estudio particularmente emblemático en este sentido: Sidney Mintz, Sweetness and Power (Nueva York: Penguin, 1985).

15 La crítica a una historia atlántica orientada hacia excesivamente hacia el oeste y hacia las conexiones transatlánticas, ignorando el vasto hinterland euroasiático que, según Peter Coclanis, servía como un escenario vibrante de intercambios e interconexiones -quizás más que el Atlántico mismo-: "Beyond Atlantic History", Atlantic History: A Critical Appraisal, pp. 345-359.
} 
costas, con poca relación hacia los interiores $-\mathrm{y}$ por lo tanto un recorte que excluye áreas vitales en lo material como en lo simbólico-. ${ }^{15}$ Materialmente, Lupiañez demuestra la integración del oeste del Río de la Plata en el Atlántico, mediante el "servicio" activo desempeñado por los tucumanos en el contexto de la invasión y tal vez patentizado con claridad en la internación forzosa de las tropas británicas capturadas. Los servicios de Tucumán sirven como despliegue simbólico, así argumenta la autora, para la mayor integración de esa ciudad en el concierto de una monarquía atlántica.

Las incursiones británicas en el imperio español no solamente ponen en relevancia coyunturas de entrelazamiento muy marcadas, como el caso de la invasión al Río de la Plata; también traen a colación otros problemas más vinculados a lo que podría ser caracterizado como geografías intelectuales o culturales. Con el ascenso de Gran Bretaña a una posición de primacía en el orden mundial en el siglo XIX, el carácter central de Londres tomó una enorme relevancia en distintas narrativas. Así, la región platense se habría constituido en una de las periferias del imperio británico. Sin embargo, la historiografía más reciente tiende a rechazar el retrotraer tal statu quo de hegemonía británica. Acaso cabe preguntarse, entonces, si expediciones como la británica al Río de la Plata, en lugar de mostrar el lugar periférico de la América hispana respecto al mundo anglosajón, demuestran su recurrente centralidad. ${ }^{16}$

El entrelazamiento de historias del ámbito británico con aquellas del mundo hispano, en este número, no se reduce al trabajo de Lupiañez. El artículo de Estefanía Blasco entrelaza distintas escalas: la biográfica de Cartherwood y el abogadoexplorador Stephens. También la de carácter local en Centroamérica como escenario de la expedición; y la perspectiva de carácter 'macro' sobre las estructuras económicas y sociales que alentaban este tipo de expediciones en el mundo anglosajón. Finalmente, es posible notar también los debates intelectuales -arqueológicos, históricos- en los que las expediciones se situaron. Entre estas estructuras se advierte la producción de un conocimiento de carácter imperial, como era típico por parte de estas expediciones. El juego de escalas entre lo personalbiográfico, lo local y lo imperial, remite al género de la historia global -e incluso a la microhistoria global-,

${ }^{16}$ El punto de Anglo-América como una periferia del mundo atlántico hispano ha sido remarcado por: Eliga H. Gould, "Entangled Histories, Entangled Worlds: The English-Speaking Atlantic as a Spanish Periphery", The American Historical Review 112:3 (Jun. 2007): pp. 764-786. 
género que también parece hacerse presente en el trabajo de Carolina Porley.

El texto de Porley presenta un juego entre lo micro y lo macro. La autora nos ofrece, por una parte la trayectoria vital de García Casalia y Ortiz de Taranco. Ambos hombres aparecen inexorablemente ligados a los movimientos migratorios que generaron el más intenso trasiego humano de carácter transatlántico a finales del siglo XIX. Ortiz de Taranco como español peninsular emigrado al Uruguay y García Casalia como hijo de inmigrantes gallegos -es decir, como uruguayo de primera generación- son ejemplos de esa

fabricante de tabacos e incluso forjó una notable actuación pública. Desde este nivel biográfico, Porley nos transporta -como si se tratara de un juego de muñecas rusas-, a los vínculos de estos hombres con el medio local, en particular con la cultura del asociacionismo español y las clases dirigentes de Montevideo en el temprano siglo XX. Este asociacionismo, por su parte, si bien tenía dimensiones locales e incluso nacionales, es presentado por la autora como participante de los movimientos de revalorización de la cultura hispana en gran escala. En la encrucijada ubicada entre las raíces biográficas españolas, la emigración a Uruguay, la "performance" de una identidad de élites con su necesario consumo cultural y la reivindicación de lo hispano, Porley ubica el coleccionismo de estos dos actores históricos.

El coleccionismo de Ortiz y García se puede emparentar con nociones historiográficas sobre narrativas"circunatlánticas" y

\footnotetext{
17 José Carlos Moya ha propuesto que la noción de Atlántico ibérico (Iberian Atlantic) sea extendida más allá del período colonial y si se quiere, de existencia de un atlántico ibérico formal. Este autor propone que es un sinsentido no considerar la existencia de un Atlántico ibérico en el siglo XIX: tiempo en que se intensificó el flujo de personas, bienes, ideas, y capitales entre la Península y las Américas. No solamente a través de estas conexiones es posible notar la existencia de un Atlántico ibérico, sino también a través de los esfuerzos por desconectar o desligar las Américas de España y Portugal -expresado en la hispanofobia o la lusofobia. José C. Moya, "The Iberian Atlantic, 1492-2012”, Theorising the Iberian Atlantic, Harold E. Braun y Lisa Vollendorf eds. (Leiden: Brill, 2013), pp. 51-73

18 Tomados según David Armitage: "La historia circunatlántica es la historia del Atlántico como zona identificable de cambio e intercambio, circulación y transmisión. ... Es la historia de gentes que cruzaron el Atlántico, que vivieron en sus orillas y que participaron en las comunidades ... La historia transatlántica es la historia del mundo atlántico contada a través de sus comparaciones." "Tres Conceptos de Historia Atlántica”, Revista de Occidente 281 (Oct. 2004): pp. 13, 17.
} 
"transatlánticas". Como una historia de movilidades y circulaciones, la narrativa de Porley puede considerarse "circunatlántica"; aunque -también- como una historia de los rasgos distintivos del hispanismo uruguayo comparado con otros hispanismos, semeja más la caracterización de "transatlántica". A través del acceso al archivo personal de Ortiz de Taranco, Porley puede situar a este personaje no solamente en un escenario atlántico, sino como un ejemplo que se aproxima a ciertos trabajos en el género de la microhistoria global. ${ }^{19}$ Ortiz de Taranco no solamente aparece en contacto con intermediarios en España, sino interactuando con bancos en Alemania -en su doble condición de empresario y coleccionista-. Este empresario, tal vez, sea un ejemplo a desarrollar como caso de estudio sobre las intersecciones entre el mercado de las producciones artísticas y la nueva historia global del capitalismo. La intersección entre lo micro y lo macro es también notable en el caso de García Casalia, a quien la autora utiliza para ilustrar ciertos puntos adicionales. Uno de éstos puede expresarse en cómo la exposición del arte en espacios íntimos refleja la intención del coleccionista de proyectar ideas sobre sí mismo. García Casalia, además de coleccionar arte español y europeo, mostró un interés por el arte uruguayo y del Río de la Plata, presentando al Uruguay como "escenario de la realización" familiar.

El trabajo de Porley también revela las potencialidades de entrelazar historias de carácter global desde sus dimensiones comparativas y conectadas con la historia de la producción de identidades y culturas nacionales. La relación entre historias globales e historias nacionales no aparece necesariamente como una de opuestos, o de las primeras como una acumulación de las segundas. ${ }^{20}$ Una metodología de historia global puede indicar cómo los procesos de formación de identidades nacionales se constituyeron de manera multilateral, contestada y generando también exclusiones. El texto ofrece un ejemplo de cómo Ortiz de Taranco y García Casalia estaban embarcados en procesos de producción de sentido sobre el valor de lo hispano, con repercusiones para lo nacional tanto en España como en Uruguay.

La propuesta de ir más allá de "lo local", creemos, ha dado

${ }^{19}$ Dos trabajos, entre varios, que remiten a este género son: Emma Rotschild, The Inner Life of Empires: An Eighteenth Century History (Princeton: Princeton University Press, 2012); Benedict Anderson, The Age of Globalization: Anarchists and the Anticolonial Imagination (Nueva York: Verso, 2013).

${ }^{20}$ Drayton y Motadel, “The Futures", p. 15. 
fruto en los estudios contenidos en este número monográfico de Humanidades. Es pertinente afirmar, nuevamente, que dicha propuesta no implica una negación de la pequeña escala en la investigación histórica. Antes bien, supone un proceso de extroversión de investigaciones de dimensión local en la búsqueda de conexiones o comparaciones más allá de sus ámbitos inmediatos. ${ }^{21}$ Hay otras formas de producción de conocimiento histórico que, partiendo de escalas mayores, parecieran naturalmente inclinadas al entrelazamiento, las comparaciones o las conexiones. Sin embargo, investigadores atentos por la escala. Como todo campo en construcción, las definiciones sobre cuál o cuáles son los aspectos más trascendentes que hacen que una historia sea global, conectada, entrecruzada, o entrelazada, sea eso y no otra cosa, han generado debates y polémicas. Pareciera que, al menos hasta el año pasado, el rasgo saliente de todas estas historias era la preferencia por lo no-nacional como objeto de estudio. Sin embargo, el renovado impacto del nacionalismo populista contribuyó a que algunos historiadores se pregunten, si acaso no se abandonó a "lo nacional" como objeto de estudio demasiado pronto. Así, la historia de lo global, de lo interconectado, de aquello que circula, de lo cosmopolita, pareciera reflejar un cierto triunfalismo respecto a la más reciente globalización y una falta de modestia sobre los "límites y disrupciones", omnipresentes en un mundo "frágil e interdependiente". Ciertos acontecimientos políticos y sociales ponen en evidencia cómo el cuestionamiento de los beneficios de un mundo híperintegrado dejó de ser un tema en los márgenes y resulta importante "considerar las fuentes de los desapegos humanos,

\footnotetext{
21 Un remedio contra la tentación de la proyección indebida puede ser, escribe la historiadora africanista Kristin Mann, puede ser el "comenzar con lo local y mirar desde adentro hacia afuera". Kristin Mann, "How Size Matters", p. 1463.

22 Drayton y Motadel, “The Futures”, pp. 4-5. Franz L. Fillafer, "A World Connecting? From the Unity of History to Global History”, History and Theory 56:1 (Mar. 2017): pp. 3-37.

23 Jeremy Adelman, "Words from Jeremy Adelman”, Journal of Global History 13 (2018), pp. 20-21.
} 
ambivalencias y resistencias a la integración". ${ }^{23}$

Junto a la crítica politica al imperialismo de historias focalizadas en grandes escalas, algunos historiadores se preguntan si acaso una hegemonía de este tipo no conllevará un empobrecimiento de la disciplina. La historiadora Joyce Chaplin, una académica especializada en la historia de la circunnavegación del planeta ${ }^{24}$ -tópico global por definición si los hay-, ha expresado su preocupación por cómo las historias interesadas exclusivamente por "lo grande" nos pueden privar de "lo cotidiano" y "lo subjetivo". Metodológicamente, la obsesión por los vínculos y conexiones también implica riesgos para el quehacer de quienes escriben historia. Las historias de mayor escala, dice Chaplin, parten de la presunción de que los historiadores tienen perspectivas que "sus objetos de estudio nunca tuvieron". ${ }^{25}$ En la creación retrospectiva de conexiones, en la extrapolación, o en la generalización, se puede perder de vista cómo las mismas conexiones pueden ser fruto de proyecciones de fuerzas o desarrollos que no fueron parte del pasado estudiado o no estuvieron dentro de las consideraciones de los actores históricos. ${ }^{26}$ Dicho llanamente: es el riesgo de conectar lo que nunca estuvo conectado o de globalizar lo que fue de dimensión estrictamente local.

En este proemio, se ha preferido ubicar los estudios de este número en diálogo con conversaciones actuales sobre historias conectadas, entrelazadas y globales, al igual que sobre la cuestión de las escalas en la investigación y la escritura histórica. A veces, sin decirlo explícitamente, los estudios reunidos en este volumen adoptan planteos y metodologías que los ponen en sintonía con propuestas y debates sobre cómo escribir historias atentas a las conexiones y entrelazamientos. Esta introducción ha tenido como propósito traer a la atención de los lectores y contribuyentes, algunos de los posibles entrelazamientos y entrecruzamientos presentes en las investigaciones de este número de Humanidades. Podría argumentarse, tal vez, que estas discusiones o afirmaciones programáticas sobre cómo escribir historia para el mañana son casi bizantinas. También se podrá decir que las historias conectadas o historias globales son meros términos "a la moda",

${ }^{24}$ Joyce Chaplin, Round About the Earth: Circumnavigation from Magellan to Orbit (Nueva York: Simon and Schuster, 2012).

${ }^{25}$ Joyce Chaplin, "How Size Matters”, pp. 1447-8.

26 Ann McGrath, "How Size Matters", p. 1461. 
que poco cambian lo sustancial del quehacer de la profesión histórica. Sin embargo, se ha creído importante participar, desde una publicación como Humanidades, en estos intercambios académicos, incluso si es para matizarlos o puntualizarlos.

Por último, pero no por ello menos importante, el editor quiere expresar su agradecimiento, en nombre de esta revista, a los ocho referís anónimos que participaron en el arbitraje de estos textos. Sus observaciones y comentarios, sin lugar a dudas, enriquecieron a cada uno de los estudios en particular y elevaron el nivel del conjunto de este número. Este volumen es, finalmente, testimonio de las posibilidades dadas por los entrelazamientos actuales entre distintas culturas académicas y de intercambio intelectual.

Álvaro Caso Bello The Johns Hopkins University - ANII 